Gomes, TLV \& Valente, GSC. (2020). Managerial competencies of nurses in the work process in primary health care. Research, Society and Development, 9(7):1-18, e366974319.

\title{
Competências gerenciais do enfermeiro no processo de trabalho em atenção básica de
} saúde

\section{Managerial competencies of nurses in the work process in primary health care}

Competencias gerenciales de las enfermeras en el proceso de trabajo en atención primaria de salud

Recebido: 07/05/2020 | Revisado: 08/05/2020 | Aceito: 08/05/2020 | Publicado: 17/05/2020

\section{Talita Lima Venetillo Gomes}

ORCID: https://orcid.org/0000-0002-0719-638X

Universidade Federal Fluminense, Brasil

Email: talitavenetillo@gmail.com

Geilsa Soraia Cavalcanti Valente

ORCID: https://orcid.org/0000-0003-4488-4912

Universidade Federal Fluminense, Brasil

Email:geilsavalente@gmail.com

\section{Resumo}

Objetivos: Identificar os principais problemas na Atenção Básica à Saúde, enfrentados pelo enfermeiro, Descrever as competências da equipe de enfermagem na Atenção Básica à Saúde e discutir os limites e possibilidades de Atenção Básica à Saúde da população em Rede Básica de Saúde, a partir das competências do enfermeiro. Trata-se de um estudo exploratório descritivo, que tem como objetivo esclarecer e proporcionar uma visão geral em dimensões mais ampliadas acerca de um determinado fato. Foram realizadas entrevistas semiestruturadas com 10 enfermeiros gestores da Atenção Básica de Saúde. Os cenários escolhidos para pesquisa foram o Programa Médico de Família (PMF) Vital Brazil, a Policlínica Regional Carlos Antônio da Silva e a Clínica Comunitária da Família do Badu, ambos da cidade de Niterói (RJ- Brasil), e uma Unidade Tipo A da Zona Oeste de Rio de Janeiro. As perguntas versaram, principalmente, sobre situações problemáticas no cotidiano do trabalho e quais as estratégias e atitudes gerenciais tomadas para solucionar ou diminuir cada uma delas. Concluiu-se que se faz necessário envidar esforços na formação permanente do enfermeiro, 
no sentido de alcançar as competências gerenciais, cada vez mais requeridas pelo mundo do trabalho.

Palavras-chave: Atenção básica de saúde; Competências gerenciais; Enfermagem.

\begin{abstract}
Objectives: To identify the main problems in Primary Health Care, faced by nurses, Describe the skills of the nursing staff in Primary Health Care and discuss the limits and possibilities of Primary Health Care of the population in the Primary Health Network, based on the nurses' competences. This is a descriptive exploratory study, which aims to clarify and provide an overview in broader dimensions about a given fact. Semi-structured interviews were carried out with 10 nurse managers of Primary Health Care. The scenarios chosen for the research were the Family Medical Program (PMF) Vital Brazil, the Policlínica Regional Carlos Antônio da Silva and the Clínica Comunitária da Família do Badu, both in the city Niterói (RJ- Brazil), and a Type A Unit in the West Zone of Rio de Janeiro. The questions mainly dealt with problematic situations in the daily work and which management strategies and attitudes were taken to solve or reduce each one. It was concluded that it is necessary to make efforts in the permanent training of nurses, in order to achieve the managerial competences, increasingly required by the world of work.
\end{abstract}

Keywords: Primary health care; Managerial skills; Nursing.

\title{
Resumen
}

Objetivos: Identificar los principales problemas en Atención Primaria de Salud que enfrentan las enfermeras, Describir las habilidades del personal de enfermería en Atención Primaria de Salud y discutir los límites y posibilidades de Atención Primaria de Salud de la población en la Red de Salud Primaria, con base en competencias de enfermeras. Este es un estudio exploratorio descriptivo, cuyo objetivo es aclarar y proporcionar una visión general en dimensiones más amplias sobre un hecho determinado. Se realizaron entrevistas semiestructuradas con 10 enfermeras gerentes de Atención Primaria de Salud. Los escenarios elegidos para la investigación fueron el Programa Médico Familiar (PMF) Vital Brasil, el Policlínico Regional Carlos Antônio da Silva y la Clínica Comunitaria Familiar Badu, ambos en la ciudad Niterói (RJ- Brasil), y una Unidad Tipo A en la Zona Oeste de Río de Janeiro. Las preguntas se referían principalmente a situaciones problemáticas en el trabajo diario y qué estrategias y actitudes de gestión se tomaron para resolver o reducir cada una. Se concluyó 
que es necesario hacer esfuerzos en la capacitación permanente de las enfermeras, para alcanzar las competencias gerenciales, cada vez más requeridas por el mundo del trabajo.

Palabras clave: Atención primaria de salud; Habilidades gerenciales; Enfermería.

\section{Introdução}

As Unidades Básicas de Saúde - instaladas perto de onde as pessoas moram, trabalham, estudam e vivem - desempenham um papel central na garantia à população, de acesso a uma atenção à saúde de qualidade (Brasil/MS, 2012). A Atenção Básica é desenvolvida através do exercício de práticas de cuidado e gestão, democráticas e participativas, com trabalho em equipe, visando atingir a populações de territórios definidos, considerando o movimento pendular presente no território em que vivem essas populações. Além disto, é de responsabilidade de todas as esferas do Governo uma infraestrutura necessária ao atendimento e contribuir com o financiamento tripartite da Atenção Básica.

Além do ato de cuidar e do atendimento direto, o enfermeiro tem o papel gerencial de criar e planejar ações, programas e atividades de atenção básica, promover uma atenção integral ao cliente com toda a equipe; participar do planejamento local de saúde e da sua promoção. Requisitar insumos para a UBS; contribuir com a atualização profissional da equipe de enfermagem e áreas parceiras. Tudo isto aliado a uma gerência de enfermagem eficiente, são fatores determinantes a uma boa manutenção e administração da unidade, portanto, requer o desenvolvimento de competências para atuar.

Durand citado por Ruthes \& Cunha (2008) diz que a evolução do conceito de competência ocorre em três dimensões distintas, os conhecimentos, as habilidades e as atitudes. Tal conceito englobou os aspectos cognitivos, técnicos, sociais e afetivos presentes em uma atividade laboral, mostrando que competência tem a ver com o conjunto de conhecimentos, habilidades e atitudes interdependentes e necessárias à conclusão de uma determinada tarefa.

O Sistema Único de Saúde (SUS) coexiste com um segmento complementar baseado na oferta de seguros e planos de saúde e, em menor medida, pelo pagamento direto no ato de consumo do serviço; ou seja, segundo a Pesquisa Nacional por Amostra de Domicilio (PNAD, 2012), o SUS responde pela saúde de 190 milhões de indivíduos enquanto os planos de saúde privados respondem por 49,2 milhões.

Segundo a Pesquisa Nacional de Saúde (2015): A maioria dos brasileiros procura pelas unidades públicas quando apresenta algum problema de saúde. Pesquisa do Ministério da 
Saúde, realizada em parceria com o Instituto Brasileiro de Geografia e Estatística (IBGE), revela que $71,1 \%$ da população foram a estabelecimentos públicos de saúde para serem atendidos. Deste total, 47,9\% apontaram as Unidades Básicas de Saúde como sua principal porta de entrada aos serviços do Sistema Único de Saúde (SUS). Atualmente são 40.674 unidades em funcionamento em todo o país.

Em um estudo realizado por Moreira e colaboradores (2011) sobre a utilização dos serviços de saúde, é relatado que: O SUS é um sistema que se apoia no conceito de cidadania ao estabelecer como diretriz o acesso universal e integral à atenção à saúde. Se essa característica é uma virtude do sistema brasileiro, tal proposição, no entanto, se constitui no desafio de atender uma população de 190 milhões de pessoas.

O exercício da enfermagem tem atribuições específicas no Decreto $n^{\circ}$ 94.406, de 8 de junho de 1987, que regulamenta a Lei $n^{\circ} 7.498$, de 25 de junho de 1986, porém o mesmo não distingue o trabalho na Atenção Básica à Saúde e outros níveis de atenção. Na aproximação com a temática, percebe-se a carência de pesquisas publicadas acerca da atuação profissional neste âmbito, tanto no que concerne à gestão, quanto as demais atividades do enfermeiro, incluindo-se a preceptoria de alunos.

Ferreira (2014) realizou um estudo de dissertação de mestrado com os Objetivos de: descrever as ações que são realizadas pelo enfermeiro na preceptoria de graduandos em UBS; identificar os saberes dos enfermeiros e as competências que ele precisa adquirir ou desenvolver para atuar na preceptoria de graduandos em UBS; discutir sobre as implicações da prática pedagógica do enfermeiro preceptor em sua própria formação permanente. Concluiu que há necessidade de discutir e repensar estratégias para orientar o interesse dos preceptores para sua formação permanente, através do desenvolvimento de competências a partir de sua própria prática, contribuindo, assim, para a valorização da própria profissão e fortalecimento do Sistema Único de Saúde.

Desta forma, percebe-se a necessidade da realização de estudos desta natureza, no sentido de explorar as competências necessárias para atuar na prática gerencial do enfermeiro em Atenção Básica de Saúde, tendo em vista que apesar de toda crise da atualidade e difíceis condições de trabalho, cabe à equipe de enfermagem decidir por não realizar suas funções, ou ter atitudes para contornar a situação e realizar, da melhor maneira possível, o atendimento a população.

Corroborando com o exposto, Soares et al (2013) em um estudo realizado sobre o impacto da organização do trabalho de enfermeiros e sua equipe, concluiu-se quanto à necessidade de um olhar específico sobre a organização do trabalho na Atenção Primária à 
Saúde, pois, diferente do que ocorre no ambiente hospitalar, existem mais condições para a diversidade de atuação da equipe de enfermagem, em especial o enfermeiro.

A atenção primária é o primeiro contato dos indivíduos com o SUS, servindo como porta de entrada, fazendo com que haja um cuidado contínuo, existindo a integralidade, sendo associada ao acolhimento, o vínculo e o trabalho em equipe na instituição, segundo o Ministério da Saúde (2012, p. 20). Em qualquer prestadora de serviço na Atenção Primária à Saúde deve-se realizar a auditoria, para avaliar o serviço prestado à comunidade. A hipótese apresentada é de que esta possa criar uma qualidade no atendimento, mostrando os fatores que devem ser revistos de acordo com a avaliação dos processos, concluindo que, além de cumprir um papel de análise técnica, esta reorienta os processos gerenciais, regulando a assistência, promovendo a equidade no acesso aos SUS e permitindo a oferta assistencial focada nas necessidades dos usuários. (Silva et al. 2015).

Com base no exposto, tem-se como objeto: As competências gerenciais do enfermeiro em Atenção Básica a Saúde. Objetivos: Identificar os principais problemas na Atenção Básica à Saúde, enfrentados pelo enfermeiro. Descrever as competências da equipe de enfermagem na Atenção Básica à Saúde. Analisar e discutir os limites e possibilidades de Atenção Básica à Saúde da população em Rede Básica de Saúde, a partir das competências do enfermeiro.

\section{Metodologia}

A abordagem metodológica utilizada é qualitativa. A pesquisa qualitativa responde a questões particulares, onde não se preocupa com a representação numérica como considera Pereira et al. (2018) e, nas Ciências Sociais, se ocupa com um nível de realidade que não é quantificado. Para Minayo (2001, p. 22), a pesquisa qualitativa trabalha com o universo de significados, motivos, aspirações, crenças, valores e atitudes, o que corresponde a um espaço mais profundo das relações, dos processos e dos fenômenos que não podem ser reduzidos à operacionalização de variáveis.

Trata-se de um estudo exploratório descritivo, que tem como objetivo esclarecer e proporcionar uma visão geral em dimensões mais ampliadas acerca de um determinado fato. Segundo Minayo (2009), este tipo de estudo compreende várias fases da construção de uma trajetória de investigação como, por exemplo, a escolha do tópico de investigação; delimitação do objeto; definição dos objetos; seleção dos instrumentos de construção/ coleta de dados e exploração de campo. 
A pesquisa de campo tem a finalidade de recolher e registrar dados referentes à pesquisa, utilizando técnicas como questionário, entrevista, formulário e outras. O enfoque do estudo em questão são entrevistas semiestruturadas a enfermeiros gestores da Atenção Básica de Saúde. Este estudo está inserido no projeto de pesquisa "Saberes e competências do enfermeiro para a preceptoria e gerência em Rede Básica de Saúde”, aprovada pelo Comitê de Ética em Pesquisa da Faculdade de Medicina da Universidade Federal Fluminense, com o número de protocolo: 320014/13. Os participantes aceitaram participar da pesquisa e assinaram o Termo de Consentimento Livre e Esclarecido, bem como a direção das unidades de saúde concederam a carta de anuência para a coleta de dados.

Os cenários escolhidos para pesquisa foram o Programa Médico de Família (PMF) Vital Brazil, a Policlínica Regional Carlos Antônio da Silva e a Clínica Comunitária da Família do Badu, ambos da cidade de Niterói (RJ- Brasil), e uma Unidade Tipo A da Zona Oeste de Rio de Janeiro. Participaram da pesquisa 10 enfermeiros gestores das referidas unidades em atenção básica de saúde.

A técnica realizada para coleta de dados foi a entrevista, como forma de obter dados das unidades e dos enfermeiros gestores, para posterior análise temática de conteúdo, segundo os objetivos do estudo. O roteiro foi elaborado com perguntas que os deixasse livres para apontar, principalmente, situações problemáticas no cotidiano do trabalho e quais as estratégias e atitudes gerenciais tomadas para solucionar ou diminuir cada uma delas.

\section{Resultados}

A primeira pergunta versava sobre as responsabilidades de gestão de cada enfermeiro em suas respectivas unidades. As respostas mais frequentes foram: Realização de escalas dos técnicos, sala de procedimentos e sala de imunização; Supervisão de equipe e de atividades dos técnicos de enfermagem e agentes de saúde; Coordenação da agenda da equipe, gerindo a lista de usuários prioritários e, assim, organizando a porta de entrada da unidade, a fim de evitar filas; Realização de planejamento estratégico da equipe e responder pela produção da mesma; Realização de planejamento de atividades na unidade e grupos educativos; educação e formação permanente da equipe, além de questões de ensino de técnicas para a equipe de enfermagem (treinamento); Liderança de reuniões da equipe em que pertence, equipe interdisciplinar, intersetorial e com a comunidade; Verificação de materiais disponíveis para o funcionamento da unidade e realizar o pedido dos mesmos. Na maioria das respostas, 
observou-se que o enfermeiro é visto como o principal membro da equipe na área de gestão e o que mais exercita a mesma; o que fornece subsídios aos gestores da unidade para tomada de decisões com maior chance de êxito.

A segunda pergunta do questionário é sobre os principais problemas enfrentados no cotidiano do trabalho. As respostas mais encontradas foram: Falha no trabalho em equipe, atribuída principalmente devido à má divisão de tarefas e atribuições, falta de ajuda e envolvimento dos colegas; Falta de insumos e recursos financeiros; falta de reconhecimento de trabalho, tanto pessoal quanto financeiro; tempo hábil escasso; problemas estruturais na unidade; Funcionários com alta rotatividade, com isto, permitindo que o vínculo seja precário; além de problemas com os usuários como a incompreensão dos mesmos com a dificuldade de agendamento pelo sistema de marcação ou ao funcionamento de serviços como o Sistema Nacional de Regulação (SISREG).

Com a extensa lista de responsabilidades de gestão do enfermeiro, há uma evidencia para a importância do ensino de Gerencia na formação e, por isso, uma suposta facilidade para lidar com tais demandas. Além da parte assistencial, existem muitas questões burocráticas que tem a necessidade de serem acompanhadas de perto, mas muitas destas poderiam ser resolvidas por qualquer outro membro da equipe, o que acaba gerando uma sobrecarga. Inúmeras são as tentativas para solucionar os problemas presentes no cotidiano do trabalho.

Por último, foi questionado de que maneira o enfermeiro gestor conseguia solucionar os problemas em seu cotidiano de trabalho. Foi relatado que muitos destes problemas não têm solução dentro da unidade, mas sim na gestão municipal, e acabam influenciando diretamente no trabalho. Porém, dentre os que são passiveis de serem solucionados, algumas respostas foram: procurar ser receptivo às pessoas e aos problemas apresentados, onde junto com os demais enfermeiros pesquisar a origem da situação para que haja uma resposta satisfatória ao bom andamento da unidade. Muita conversa e reuniões com a equipe e demais profissionais da unidade, onde são levados questionamentos, discussões dos casos, avaliação dos planejamentos e apresentadas sugestões para melhorias e melhor funcionamento da equipe. Apontando a sobrecarga do enfermeiro e dividindo tarefas para amenizar este problema.

Foram apontadas, também, soluções para questões assistenciais, onde o usuário é chamado para discutir se o atendimento está sendo satisfatório; realização de sala de espera; sensibilização da equipe para orientações, principalmente por parte dos agentes comunitários de saúde, pois entendem melhores formas de conduzir com cada família, visando à melhoria dos problemas e tentando conduzir de maneira que haja benefício para o usuário. 
Entendimento das dificuldades familiares, e até busca ativa dos pacientes, bem como das crianças para vacinação e das gestantes que não querem realizar o pré-natal.

\section{Discussão}

\section{$1^{\mathrm{a}}$ Categoria: Problemas na Atenção Básica à Saúde, enfrentados pelo enfermeiro}

Para o enfermeiro da atenção básica, intensificam-se os cuidados tanto individuais quanto coletivos, além das ações gerenciais. A enfermagem é uma das categorias da saúde mais mobilizadas para o gerenciamento das unidades básicas de saúde, sendo encarregada do compromisso da viabilização do SUS, incentivando a participação da equipe na organização e produção de serviços de saúde, para atender às reais necessidades dos usuários, trabalhadores e instituição, tudo isto aliada aos demais profissionais (Fernandes et al, 2010). Entretanto, limitações dificultam no funcionamento do trabalho, como relata um dos participantes da pesquisa:

Nesta unidade de saúde temos problemas estruturais e por conta disso, não conseguimos nos concentrar em um campo específico de ação da enfermagem. Além disso, há pouca disponibilidade de recursos financeiros para a unidade; funcionários com vínculos precários; alta rotatividade de funcionários, o que prejudica a formação permanente dos técnicos de enfermagem. (Participante B)

Para muitos dos participantes, a questão da dificuldade no repasse de recursos financeiros para a unidade foi apontada como problema, principalmente por acarretar na falta de insumos para manutenção do cuidado. Outra participante foi além, alegando "[...] Falta de reconhecimento pelo trabalho (tanto pessoal, como financeiro)" (Participante F), onde é perceptível em seu relato descontentamento com a remuneração de seu trabalho.

Falando em um contexto de saúde do trabalhador na atenção básica, a não disponibilidade de equipamentos e insumos necessários para a prática profissional desdobrase em um conjunto de problemas de ordem objetiva e subjetiva para o trabalhador: desorganização, interrupções constantes do trabalho, exposição a riscos diversos, tanto para a pessoa que está sendo cuidada, como para o profissional, ansiedade e sensação de trabalho incompleto (David et al., 2009). 
$\mathrm{O}$ aparecimento de condições de trabalho adversas para a equipe de enfermagem pode abrir caminho para mal entendidos e até erros. Curiosamente cabe enfatizar que os enfermeiros mobilizam saberes, transformando-os em competências profissionais no âmbito da Atenção Básica, no intuito de compensar as adversidades. (Ferreira 2014).

Sobre aceitar condições de trabalho desfavoráveis é afirmar a ideia de que os interesses do capital estão acima dos interesses da saúde da população, relata Sanna (2007) em seu estudo. Também relata sobre o processo de trabalho Participar Politicamente, que não significa que o enfermeiro deve filiar-se a um órgão de classe, partido político ou organizações, mas sim, que todo julgamento moral e atitude que o profissional corresponde é uma forma de participação política.

Acrescenta-se ainda que: Para transformar a realidade, é preciso atuar sobre o objeto da participação política, que é constituído pela força de trabalho em enfermagem e sua representatividade social, que tem nas entidades de classe sua concretização. Dessa forma, quando o profissional decide se filiar a uma dessas entidades ou quando se envolve com suas atividades, seja na qualidade de associado ou dirigente, conquista condições plenas de agir sobre o objeto. Mas não é só este o meio de fazê-lo.

Outro ponto relevante, apontado por vários participantes, é a sobrecarga de tarefas. Segundo o Conselho Federal de Enfermagem (COFEn) o exercício da Enfermagem é regulamentado e seus profissionais têm suas atribuições especificadas no Decreto $\mathrm{n}^{\circ}$ 94.406, de 8 de junho de 1987, que regulamenta a Lei $n^{0}$ 7.498, a qual descreve quem são os profissionais de enfermagem e suas atribuições, porém não distingue o trabalho do enfermeiro na área da Atenção Primária a Saúde (APS) dos demais níveis de atenção à saúde.

Soares e colaboradores (2013) falam: A APS requer muitas habilidades dos profissionais de saúde e, por consequência, dos enfermeiros. Existe falta de especificidade nas atribuições do enfermeiro, que pode ter sua origem na atuação dos próprios profissionais, que ainda não se apropriaram da finalidade precípua de seu trabalho no cotidiano das UBS, agregando funções e fazeres que não lhes são próprios.

Sobre esse aspecto, corroborando com o exposto acima, encontramos que: $\mathrm{O}$ Enfermeiro está presente na maioria das ações desenvolvidas na Atenção Básica/Saúde da Família, sejam tais ações de ordem técnica, científica, ou interpessoal, o que contribui para a discussão de que a prática desse profissional está sendo o resultado de uma transformação dos processos de trabalho em saúde, requerendo a inauguração de novas práticas a partir do estabelecimento de relações dialógicas, da produção de novos saberes, da formação 
profissional que promove novas formas de pensar e agir em saúde no contexto do Sistema Único de Saúde (Silva, 2013).

Nesse sentido, são relevantes as iniciativas de organização do trabalho por parte dos enfermeiros gerentes. Foram identificadas várias falas sobre a falta da união entre a equipe, como, por exemplo, explicitou a Participante C: "Falha do trabalho em equipe, através da falta de divisão de atribuições". É fundamental para um bom funcionamento que o trabalho seja operacionalizado em equipe, identificando as expectativas desejadas sobre a atuação e explicitando as atribuições profissionais.

Sob este prisma, Soares e colaboradores (2013) compreenderam que existe a necessidade de um olhar específico para a organização na atenção primária, pois há maiores condições para a diversidade da equipe de enfermagem, diferentemente do ambiente hospitalar, em especial para o enfermeiro.

Witt et al (2006) falam sobre a dificuldade no posicionamento profissional: As enfermeiras têm buscado modificar sua prática, a fim de avançar no atendimento integral de saúde. No entanto, têm encontrado dificuldades na determinação de suas competências, no trabalho em equipe multiprofissional e na indefinição da programação da assistência à saúde em nível local.

Em contrapartida, Assad \& Viana (2003) falam sobre a adaptação necessária para o enfermeiro, indo do conhecimento apreendido durante sua formação até a realidade encontrada no local de trabalho, muitas das vezes vivenciando atribuição de funções profissionais que não é pertinente. E, por isso, a importância da prática, onde o enfermeiro adquire bagagem profissional e consegue ter a percepção de falhas no funcionamento do trabalho. Acrescentam que: saberes práticos compõe o conjunto de instrumentos aos quais os enfermeiros recorrem no dia-a-dia do exercício da profissão; em outras palavras, abrange o conjunto de conhecimentos elaborados pelo próprio enfermeiro, a partir das suas experiências na labuta cotidiana.

\section{$2^{\mathrm{a}}$ Categoria: Competências da equipe de enfermagem na Atenção Básica à Saúde}

Perrenoud (2001) afirma que cada pessoa tem uma experiência diferente da outra e estas desenvolvem competências adaptadas a seu mundo, para solucionar com pertinência e eficácia uma série de situações de seu cotidiano. Uma das categorias para identificar as competências fundamentais para a autonomia das pessoas é saber formar e conduzir projetos e desenvolver estratégias, individualmente ou em grupo. Vários dos participantes mostraram 
como importante o trabalho em equipe, como, por exemplo, a Participante F onde fala que "Converso com a equipe, me reúno com os demais profissionais da unidade sobre melhorias".

[Consegue solucionar os problemas] Com muita conversa com a equipe (Reunião de equipe, discussão de caso) que está todos os dias atuando comigo, pois vemos de forma diferente as situações encontradas no dia-a-dia, com os Agentes Comunitários de Saúde envolvidos, temos um profissional que atua diretamente com os pacientes no qual entende a melhor forma de conduzir com cada família cadastrada (Participante A).

Em relação ao trabalho em equipe, André \& Ciampone (2007) afirmam que para ser um enfermeiro gestor na saúde competente: A produção do conhecimento na área de administração de serviços de saúde indica que o gestor, enquanto líder, deve saber trabalhar com sua equipe, de maneira a desenvolver os conhecimentos e habilidades do grupo, buscando sinergia e desenvolvimento contínuo do mesmo.

Sobre as competências gerenciais dos enfermeiros, Fernandes et al (2010) consideram ser a análise crítica para tomada de decisão gerencial e o desenvolvimento do pensamento autônomo; organização de redes de serviços de saúde; desenvolvimento de instrumento para análise da situação de saúde e provisão de serviços e elaborar estratégias de intervenção; identificação de potencialidades e limitações institucionais que diminuam ou impeçam a efetividade das ações de saúde; realização de planejamento e programação, fundamental à análise de situação e elaboração de propostas de intervenção, utilização do sistema de informação, avaliando suas potencialidades e limitações; desenvolvimento dos conhecimentos gerenciais a partir de novos enfoques e modernas técnicas de gestão, entre outras.

Assad \& Viana (2003) defendem a ideia de que através da experiência, o profissional constrói o seu conhecimento, afirmando: [...] Esse processo (construir conhecimento) determinará as suas percepções, interpretações e as direcionará na tomada de decisões que lhe permitirão enfrentar os problemas do cotidiano de trabalho. Para que o conhecimento gere competências, é necessário que os saberes dos profissionais sejam mobilizados através de seus esquemas de ações, decorrentes da percepção, avaliação e decisão, desenvolvidos na prática.

A maior parte do trabalho de enfermagem na gerência está voltada para as questões de recursos humanos, porém existem outras áreas que devem ter atenção deste profissional, 
como a área de custo, da regulação, da avaliação do serviço prestado. Pode-se ver este aspecto apresentado na fala de um dos enfermeiros participantes da pesquisa:

No meu cotidiano me deparo com diversos problemas que influenciam diretamente no meu trabalho. Muitos desses problemas não têm solução dentro da unidade, mas sim na gestão municipal. Porém, os problemas que são possíveis de resolver internamente, eu procuro ser receptivo às pessoas e aos problemas apresentados e, junto com os demais enfermeiros, pesquisamos a origem da situação para darmos uma resposta satisfatória ao bom andamento da unidade de saúde (Participante B).

Sobre este aspecto, acrescentam Ciampone \& Kurcgant (2004) que nesse processo dáse a mercantilização e expansão da medicina privada, dos convênios celebrados pela Previdência Social entre hospitais, clínicas e laboratórios, direcionando a forma de pagamento por unidade de serviço. Nesse contexto, o gerenciamento em enfermagem exerceu o papel preponderante de controlar os recursos para a assistência, tanto no que tange aos recursos humanos, quanto aos materiais, físicos e financeiros. André \& Ciampone (2007) dizem que o gerenciamento local de saúde deve ser desenvolvido por profissional competente, capaz de liderar e agregar valor, aumentando o potencial de sua equipe e conjugando os esforços para utilizar recursos financeiros, tecnológicos, materiais e humanos, de modo a aumentar a resolutividade do serviço na área de abrangência, em conformidade com o modelo assistencial pautado na epidemiologia social.

A relação do enfermeiro com outros profissionais e até mesmo com o usuário, no espaço em que ocorre o gerenciamento da enfermagem, são condições que fazem parte e demonstram determinadas características no desenvolver do trabalho deste profissional. Sanna (2007) fala sobre a importância no planejamento e na realização de ações no local de trabalho pelo enfermeiro gerente. O processo de trabalho gerenciar em Enfermagem tem como objeto os agentes do cuidado e os recursos empregados no assistir em enfermagem. Com isto, a enfermagem não deve se ocupar apenas do cuidar, pois não existe cuidado se não houver a coordenação do processo de trabalho assistir em enfermagem, que compõe a finalidade do processo de gerenciar.

Outra razão pela qual há tanto mal estar quando se aborda o processo de trabalho administrar, é porque ele tem como agente o enfermeiro, o único profissional que domina os métodos empregados nesse processo, que são o planejamento, a tomada de decisão, a supervisão e a auditoria. [...] Assim, o enfermeiro se torna capaz de prover condições para o 
cuidado se efetivar com eficiência e eficácia, que é o produto do processo de trabalho administrar em enfermagem. Essas são as razões pelas quais cabe exclusivamente ao enfermeiro ser agente desse processo.

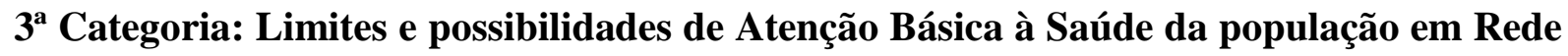

\section{Básica de Saúde}

Em nossa sociedade, devido a modernidade, a busca pela eficácia justifica a reorganização permanente no trabalho, onde, por consequência, priorize uma rápida evolução das competências em detrimento do respeito às tradições, ao status, aos diplomas e às qualificações formais.

Desenvolver as próprias competências passou a ser uma simples condição e não mais uma escolha. Isto torna raros os setores nos quais possibilitam sobreviver sem que haja um aprendizado (Perrenoud 2011). O gerenciamento de enfermagem permite a atuação em vários eixos, como a capacitação constante da equipe, com educação permanente, assim como descreve alguns dos participantes:

Ajudo no trabalho de gestão do corpo de enfermagem, principalmente na área de educação e formação permanente. Por vezes forneço subsídios aos gestores da unidade para tomar decisões com maior chance de êxito (Participante B).

O enfermeiro de equipe na estratégia de saúde da família é, na minha opinião, o que mais exercita a gestão na unidade (com exceção do gestor) [...] (Participante C).

A formação permanente do profissional de saúde permite, além do crescimento pessoal e profissional, melhorias no atendimento prestado ao cliente, fazendo com que haja benefício mútuo a partir disto. Alguns participantes da pesquisa ressaltaram a importância do gerenciamento na saúde para ser resoluto, assim como é descrito em um dos princípios do SUS, procurando resolver os problemas para uma melhor manutenção do trabalho e buscando com que sua unidade seja verdadeiramente a porta de entrada para a saúde da população.

Os enfermeiros têm muitas atividades de gestão, é visto como o principal membro da equipe neste quesito. Planeja as atividades da unidade, supervisiona, faz escalas, 
Research, Society and Development, v. 9, n. 7, e366974319, 2020

(CC BY 4.0) | ISSN 2525-3409 | DOI: http://dx.doi.org/10.33448/rsd-v9i7.4319

verifica se há material para o funcionamento da unidade, concede informações para estabelecimento de prioridades (Participante G).

Planejo as ações com base na necessidade, supervisiono os técnicos e agentes, faço escalas, coordeno as agendas, organizo porta de entrada evitando filas (Participante $\mathrm{H})$.

[...] o profissional enfermeiro inicia sua atuação com a responsabilidade de gerencia administrar as unidades de saúde como: Pedido de material para curativo; materiais permanentes para as unidades; escalas das equipes, envio de aparelhos para manutenção; a supervisão dos ACS; das agendas de marcação de consulta (Participante A).

Witt et al (2006) esclarece que a competência, ou habilidade de prestar serviços profissionais específicos, pode ajudar a definir o papel da enfermagem e fornecer evidência do cuidado prestado, quando é utilizada na prática, na educação e na regulação. Os profissionais de saúde devem assegurar que sua prática seja realizada de forma integral e contínua com as demais instâncias do sistema de saúde, sendo capaz de pensar criticamente, de analisar os problemas da sociedade e procurar soluções para os mesmos, tendo em conta que a responsabilidade da atenção à saúde não se encerra com o ato técnico, mas, sim, com a resolução do problema de saúde, tanto em nível individual como coletivo.

Percebe-se, portanto, a grande responsabilidade do enfermeiro enquanto gestor, no que concerne à necessidade de adquirir e desenvolver cada vez mais competências gerais e gerenciais para atuar de modo eficaz na gestão dos serviços, tendo em vista o seu potencial de ação e as demandas advindas da prática.

\section{Considerações Finais}

A partir dos resultados obtidos, respondeu-se aos objetivos propostos e por meio deles, mostrou-se a importância de estudar as competências gerenciais do enfermeiro, principalmente visando à educação permanente desses profissionais. As transformações na formação do enfermeiro vêm ocorrendo em passos curtos em relação à transformação prática, onde o profissional acaba se adaptando ao ambiente de trabalho, embora houvesse a necessidade de transformação junto com a capacitação para atuar em âmbitos assistenciais e 
gerenciais em saúde. Grande parte da sobrecarga do enfermeiro vem associada à escassez desses profissionais, a baixos salários, o que faz com que este procure mais de uma fonte de renda, gerando um maior cansaço físico e mental. Tarefas más distribuídas fazem com que seja um trabalho visto como desgastante, sem reconhecimento e sem autonomia.

Com a chegada de novos profissionais e mudanças atitudinais, ocorrem mudanças importantes para a enfermagem que necessitam cada vez mais de esclarecimentos e discussões sobre a competência e quais competências deve ter o enfermeiro, desde sua base na formação. Assim, com a necessidade constante de organização do SUS, os enfermeiros inseridos em cargos de chefia e liderança se tornarão cada vez mais competentes na gestão da saúde, imprimindo características no processo de trabalho destes, visando, também o relacionamento entre profissional, usuário e demais trabalhadores da equipe, à medida que investirem na sua própria formação permanente, que requer uma atitude pessoal de aceitar esta necessidade.

O processo de mudança só ocorre quando muda a forma de pensar e agir dos membros da equipe, enfrentando seus próprios limites, mudando sua filosofia e seu contexto sobre as formas do cuidar, da assistência e da gerência, enfrentando os problemas diários, buscando sempre conduzir de maneira que ocorra beneficio mútuo com o usuário da saúde. Ter um bom gerenciamento é uma qualidade que faz com que o enfermeiro saiba avaliar e desenvolver competências, não só em si mesmo, mas em toda equipe.

\section{Referências}

Brasil. (2012). Política Nacional de Atenção Básica. Brasília: Ministério da Saúde. (Série E. Legislação em Saúde). Ministério da Saúde.

Brasil. (2015). 71\% dos brasileiros têm os serviços públicos de saúde como referência. Pesquisa Nacional de Saúde. Portal da Saúde. Disponível em:

<http://portalsaude.saude.gov.br/index.php/cidadao/principal/agencia-saude/17961-71-dosbrasileiros-tem-os-servicos-publicos-de-saude-como-referencia>

Ciampone MHT \& Kurkgant P. (2004). O ensino de administração em enfermagem no Brasil: o processo de construção de competências gerenciais. Revista Brasileira de Enfermagem, Brasília, 57(4):401-407. Disponível em: <http://www.scielo.br/scielo.php?script=sci _arttext\&pid=S0034-71672004000400003\&lng=en\&nrm=iso>. 
Cruz Neto O. (2002). O trabalho de campo como descoberta e criação. In: Minayo MCS. (Org.). Pesquisa social: teoria, método e criatividade. 21.ed. Petrópolis: Vozes.

Durand T. (1998). Forms of incompetence. In: $4^{\text {th }}$ Internacional Conference on CompetenceBased Management. Oslo (NW). Disponível em: <http://www.cmi-strategies.com/wpcontent/uploads/2012/05/Thomas-Durand-2000-Forms-of-Incompetence.pdf>

Fernandes MC et al. (2010). Análise da atuação do enfermeiro na gerência de unidades básicas de saúde. Revista Brasileira de Enfermagem, Brasília, 63(1):11-15, Feb Disponível em: <http://www.scielo.br/scielo.php?script=sci_arttext\&pid=S0034-1672010000100002 $\& \operatorname{lng}=\mathrm{en} \& \mathrm{nrm}=\mathrm{iso}>$.

Ferreira FDC. (2014). Os saberes e competências do enfermeiro para a preceptoria de graduandos em unidade básica de saúde: implicações na sua formação permanente. Dissertação de Mestrado Profissional em Ensino na Saúde. Escola de Enfermagem Aurora de Afonso Costa. Universidade Federal Fluminense.

Fleury MTL \& Fleury A. (2001). Construindo o Conceito de Competência. RAC, Edição Especial 2001: 183-196. Disponível em: <http://www.scielo.br/pdf/rac/v5nspe/v5nspea10. $\mathrm{pdf}>$

Gomes KJS \& Paula SHB. (2014). O enfermeiro e o gerenciamento na Estratégia Saúde da Família. BIS. Boletim do Instituto de Saúde; 15(2). Disponível em: <http://pesquisa.bvsalud.org/enfermagem/resource/pt/ses-30140>

Matumoto S et al. (2012). Produção de atendimentos de enfermeiros em unidades da rede básica de saúde. Revista Latino-Americana Enfermagem. 20(4) Ribeirão Preto. Disponível em: <http://www.scielo.br/scielo.php?script=sci_arttext\&pid=S0104-1692012000400011 \&lng=en\&nrm=iso\&tlng=en>

Minayo MCS (org.). (2010). Pesquisa social: teoria, método e criatividade. 29. ed. Petrópolis, RJ: Vozes. 
Pereira AS, Shitsuka, DM, Pereira, FJ \& Shitsuka, R. (2018). Metodologia da pesquisa científica. [e-book]. Santa Maria. Ed. UAB/NTE/UFSM. Acesso em: 15 maio 2020. Disponível em: https://repositorio.ufsm.br/bitstream/handle/1/15824/Lic_Computacao _Metodologia-Pesquisa-Cientifica.pdf?sequence=1

Perrenoud P. (2001). Ensinar: agir na urgência, decidir na incerteza. 2.ed. Porto Alegre: Artmed.

Porto SM, Ugá MAD, Moreira RS. (2011). Uma analise da utilização de serviços de saúde por sistema de financiamento: Brasil 1998 -2008. Ciencia \& Saúde Coletiva. 16 :3795-806p. Disponível em: http://www.scielo.br/pdf/csc/v16n9/a15v16n9.pdf.

Ruthes RM \& Cunha ICKO. (2008). Entendendo as competências para aplicação na enfermagem. Revista Brasileira de Enfermagem. 61(1). Brasília Jan./Feb. Disponível em: <http://www.scielo.br/scielo.php?script=sci_arttext\&pid=S0034-71672008000100017>.

Ruiz G. (2012). Quem usa o Sistema Único de Saúde? [Internet]. Rio de Janeiro: Portal DSS Brasil; Abr 09. Disponível em: http://dssbr.org/site/?p=9534\&preview=true.

Silva et al. 2015. Auditoria como instrumento de gestão na atenção primária à saúde. Gerais: Revista Saúde Pública SUS MG; 3(1): 70-8. Disponível em: http://revistageraissaude.mg.gov.br/index.php/gerais41/article/view/310/161

Soares CES, Biagolini REM \& Bertolozzi MR. (2013). Atribuições do enfermeiro na unidade básica de saúde: percepções e expectativas dos auxiliares de enfermagem. Revista Escola de Enfermagem USP . 47(4):915-21. São Paulo, 2013. Disponível em: https://dx.doi.org/10.1590/S0080-623420130000400020

Witt, R, Almeida, M \& Araújo, V. (2006). Nurses' competencies in primary health care: a Delphy technique study. Online Brazilian Journal of Nursing, 5(3). doi: https://doi.org/10.5935/1676-4285.2006546 
Research, Society and Development, v. 9, n. 7, e366974319, 2020

(CC BY 4.0) | ISSN 2525-3409 | DOI: http://dx.doi.org/10.33448/rsd-v9i7.4319

Porcentagem de contribuição de cada autor no manuscrito

Talita Lima Venetillo Gomes - 50\%

Geilsa Soraia Cavalcanti Valente - 50\% 